\title{
Sustainable Growth from a Factor Dependence and Technological Progress Perspective: A Case Study of East China
}

\author{
Ying Liu, ${ }^{1}$ Wan-Ming Chen, ${ }^{2}$ Sheng-Yuan Wang ${ }^{D},{ }^{1}$ and Xiao-Lan Wu ${ }^{1}$ \\ ${ }^{1}$ Nanjing Xiaozhuang University, Nanjing, Jiangsu 211171, China \\ ${ }^{2}$ Nanjing University of Aeronautics and Astronautics, Nanjing, Jiangsu 210016, China \\ Correspondence should be addressed to Sheng-Yuan Wang; 56439976@qq.com
}

Received 15 June 2021; Revised 11 August 2021; Accepted 24 August 2021; Published 2 September 2021

Academic Editor: Daqing Gong

Copyright $\odot 2021$ Ying Liu et al. This is an open access article distributed under the Creative Commons Attribution License, which permits unrestricted use, distribution, and reproduction in any medium, provided the original work is properly cited.

\begin{abstract}
The paper constructs an economic growth model that contains human, physical capital, innovation, and energy factors and estimates the output elasticity of seven provinces and cities in East China in the period of 2004-2018. Having calculated the contribution rate of these different factors to economic growth, the paper finds that factors of production have a different elasticity that impacts the growth of different regions and industries and notes that energy and physical capital are the most significant factors for the growth of primary and secondary industries. This highlights that industrial growth has not freed from the path dependence of extensive input, and the authors cite Shanghai and Jiangsu as typical regions in this regard. The former's growth largely depends on physical capital and energy, and the latter's growth depends on the input of diverse elements including innovation. The latter is better suited to the needs of the "new normal" economic growth. The authors construct a simulation model of economic growth based on system dynamics, and system simulation results show that energy and material capital investment not only have the most significant effect on economic growth in East China but also provide clear evidence of extensive economic growth. The paper then demonstrates that increasing the optimal allocation of input factors and the rational flow between regions is conducive to improving output efficiency and provides the results of the Malmquist index calculation: on the whole, there is no obvious technological progress in East China. Shanghai, Jiangsu, and Zhejiang are, however, provincial-level regions of this part of the country which demonstrate significant technological progress in East China. In conclusion, the paper suggests that this region of China will be unable to maintain its current level of economic growth because of the combined influence of factor input constraints and insufficient technological progress.
\end{abstract}

\section{Introduction}

Since 2011, China's economic growth has marked a clear departure from sustained high level of growth. In a background of overall economic deceleration, increasing numbers of provincial-level regional economic aggregates have settled on a new level. In 2015, 10 provincial regions in the country had a GDP per capita in excess of US $\$ 10,000$, including Beijing, Tianjin, Shanghai, Zhejiang, Jiangsu, Inner Mongolia, Guangdong, Fujian, Liaoning, and Shandong. In 2019, per capita GDP in East China exceeded US $\$ 10,000$ and five provincial-level regions attained this level: Shanghai, Zhejiang, Jiangsu, Fujian, and Shandong. Anhui and Jiangxi, meanwhile, followed close behind with a GDP per capita of around US\$8,000. At a time of a general economic slowdown, the economic growth from East China was a bright spot. Research into the contribution of factors and technological progress to economic growth in these regions will help to analyze the driving force of economic growth and to identify paths to sustainable economic development.

In the Economic Accounting Model, the Cobb-Douglas Production Function (C-D function) is more commonly used, and its basic input factors are labor (human capital) and capital (physical capital). The study of economic growth only considers total human capital, which is insufficient to solve the problem, and accordingly some scholars have sought to verify the contribution of structural variables of human capital to economic growth by undertaking empirical 
research. The researchers suggest that when human capital is combined with different levels of education, it has divergent effects on economic growth [1-4]. Some researchers therefore assert that the proportion of high-quality human capital among employees should be increased, and they argue that the upgrading of human capital structure will help to maintain the economic growth rate. They also suggest that when human capital is engaged at different levels of education, its output will vary [5-9].

When building economic accounting models, researchers mainly draw on the example of developed Western countries that have already achieved industrialization, despite the fact that their economic growth patterns are different from those of developing countries. As the research object expands, the traditional accounting model will struggle to sufficiently elaborate countries and regions that are developing towards industrialization, which is why many researchers incorporate energy factors into their research [10-14]. It has been claimed that China entered the late stage of industrialization during the "12th Five-Year Plan" period [15]. Other scholars, meanwhile, seek to incorporate natural resources into their expanded growth model for economic analysis [16].

With the development of knowledge economy and the advent of scientific and technological globalization, innovation ability will play a key role in realizing the goal of social and economic development. Therefore, the research on the allocation of scientific and technological resources mainly compares and analyzes the investment status of scientific and technological resources, the allocation of $R \& D$ activities, and the effect of scientific and technological policies in various countries, so as to evaluate the effect and applicability of technological progress [17].

There are abundant researches on the role of technological innovation in China's economic growth. The current economic growth model has a relatively single choice of input factors; therefore, it is difficult to truthfully reflect the actual situation of China's economic growth. In order to make up for the above defects, this study uses seven provinces (city) in East China, Shanghai, Zhejiang, Jiangsu, Fujian, Shandong, Anhui, and Jiangxi, as samples to study the effects of physical and human capital, technology, and energy on economic growth and constructs a variety of input factors on this basis. It uses the Production Function Model to quantitatively analyze the output elasticity of factors to economic growth and the System Dynamics Method to build an economic growth simulation system. It conducts policy simulation from a perspective that considers the impact of factor input on output and seeks to identify a path that will enable the optimal allocation of factors in the process of sustained economic growth.

\section{Literature Review}

Lucas divides capital into material capital and human capital, and he believes that human capital contributes to the differences in economic growth among countries [18]. The situation of human capital determines the type of technological progress and the efficiency of the use of advanced technology in actual production. The contribution of capital to economic growth includes the role of technology and human capital. The growth of material capital reflects the technical structure of economy, which is determined by human capital [19]. Many studies have confirmed that human capital is conducive to improving economic growth rate and promoting physical capital investment [20] and to improving total factor productivity [21]. In fact, one of the most important determinants of economic growth is the allocation and balance of human capital among different departments [22].

Human capital is composed of people with different levels of education. Relatively speaking, high-quality human capital has a more important impact on technological innovation. The exploration and research on relevant knowledge can not only promote technological innovation directly but also extend knowledge to low-quality human capital. Based on the data of OECD member countries, Vandenbussche et al. found that the part of human capital with higher education has a significant role in promoting total factor productivity [23].

However, some studies have pointed out that there is no significant relationship between human capital and economic growth [24]. Other studies have also confirmed that human capital does not promote output $[25,26]$. The role of human capital in promoting economic growth is closely related to the type and development stage of a country. Krueger and Lindahl found that the positive correlation between human capital and output growth only occurred in low-income countries [27]. On the contrary, Pritchett's transnational empirical research shows that there is a significant negative correlation between the growth of total factor productivity and the growth of average human capital [26].

The economic growth effect of human capital is affected by the industrial structure. The transformation of industrial structure suitable for human capital can optimize the allocation of human capital, improve the output efficiency of human capital, and contribute to sustained and rapid economic growth. On the contrary, the mismatch between human capital and economic structure will generate crowding-out effect, which will lead to higher unemployment rate and imbalance of labor market. Human capital and technological innovation are important factors affecting economic growth, and human capital, the comprehensive embodiment of ability, knowledge, and technology, is the basis of technological innovation. Based on international data, many studies have confirmed that human capital plays a positive role in promoting technological innovation [28]. Human capital can not only affect production as a factor of production but also indirectly affect production by affecting technological progress [18]. Technological progress is formed by people's response to market incentives and is also the core of long-term economic growth. The significance of human capital is that it determines the production of knowledge and technology and then determines the growth of knowledge and technology [22].

There have been many studies on human capital and economic growth, but the conclusions are not consistent. 
Even in the same country and region, this relationship may be changing. Then, for China, is there such a relationship of stage change? How is human capital better accumulated in order to effectively promote regional economic growth, especially in the context of the new era? How human capital is made better use of to promote innovative development, so as to promote high-quality regional economic growth? With the development of economy and society, the effect of technological progress on economic growth is becoming more and more obvious. According to the endogenous economic growth theory, technological progress is the core of economic growth [26]. With the development of knowledge economy and the globalization of science and technology, a country's innovation ability plays a key role in supporting social and economic development [29]. The quantity and quality of technological innovation elements provide an important basis for national innovation capacity [30].

The level of regional innovation contributes to the continuous improvement of the economic competitiveness and the long-term sustainable development of regional economy. The level of regional innovation efficiency is an important index to measure the innovation discovery ability in a region. The existing research on innovation efficiency mainly focuses on the role, evaluation, and measurement of innovation investment in economic growth and its influencing factors. Scholars have obtained different methods to measure innovation efficiency from empirical research on regional innovation system in specific regions [31]. Methods including data envelopment analysis (DEA) [32], factor analysis [33], and stochastic frontier model [34] have been used to measure innovation efficiency. Chen and Guan [35] applied relational network data envelopment analysis to the systematic evaluation of innovation efficiency of China's innovation system [35]. Their results show that, in the whole process from technology development to commercialization, only one-fifth of China's regional innovation system is at the best forefront. Dzemydaite et al. [36] assessed Eastern Europe and the central European Union region based on the efficiency level of the innovation system. These existing studies focus on specific regions to measure their innovation efficiency and explore how to distribute innovation resources more equitably and improve innovation efficiency [36].

There are few studies on technical efficiency based on multifactor production function. Taking the extended multifactor production function as the basis of input-output index system can improve the current research on innovation efficiency. The nonparametric characteristics of data envelopment analysis can be optimized if combined with production function, which provides a theoretical basis for efficiency research.

\section{Materials and Methods}

3.1. Construction of Economic Growth Model. In the Economic Accounting Model, the Cobb-Douglas Production Function (C-D function) is more commonly used, and these basic input factors are labor (human capital) and capital (physical capital). In this study, labor factors are replaced by human capital elements. We can get

$$
Y=A K^{\alpha} H^{\beta},
$$

where $A$ represents technological progress, $K$ represents physical capital, and $H$ represents total human capital. $\alpha$ and $\beta$ are the output elasticity.

Considering the education level of human capital differences and expanding the traditional C-D production function, we can get

$$
Y=A K^{\alpha} H_{1}^{\beta_{1}} H_{2}^{\beta_{2}} H_{3}^{\beta_{3}},
$$

where $H 1$ is the primary human capital (the number of elementary school educations), $H_{2}$ is the intermediate human capital (the sum of the number of junior high school and high school educations), and $H_{3}$ is the advanced human capital (the number of college educations and above). $\beta_{1}, \beta_{2}$, and $\beta_{3}$ are output elasticity. It is therefore necessary to take energy factors into account when considering the accounting model of China's economic growth. Considering the role of energy consumption in economic growth, we can get

$$
Y=A K^{\alpha} H_{1}^{\beta_{1}} H_{2}^{\beta_{2}} H_{3}^{\beta_{3}} E^{\gamma},
$$

where $E$ is energy consumption and $\gamma$ is output elasticity. The "new normal" of the economy requires innovation to catalyze growth, and so innovation elements need to be considered. Different indicators can be used to describe innovation factors in the research. Enterprises purchase technology and use it for production, which reflects the direct effect of innovation factors on production. In this study, "technical turnover" is therefore used to reflect the investment of innovation factors. In equation (4), $T$ is the input of innovation elements and $\theta$ is the output elasticity:

$$
Y=A K^{\alpha} H_{1}^{\beta 1} H_{2}^{\beta 2} H_{3}^{\beta 3} E^{\gamma} T^{\theta} .
$$

The production function usually uses two models with constant and variable returns to scale. In acknowledging that the economic development environment has changed rapidly in recent years and taking into account the fact that constant returns to scale can be regarded as a special state with variable returns to scale, this study uses the C-D function with variable returns to scale. Taking the logarithm of the two sides of formula (4), we can get

$$
\begin{aligned}
\ln Y= & \ln A+\alpha \ln K+\beta_{1} \ln H_{1}+\beta_{2} \ln H_{2} \\
& +\beta_{3} \ln H_{3}+\gamma \ln E+\theta \ln T .
\end{aligned}
$$

Equation (5) suggests that regression analysis can be used to estimate the output elasticity coefficient of each factor.

3.2. Collation of Input and Output Data. This study uses education level classification indicators to illustrate the heterogeneous human capital input in different regions. The measured regional fixed asset stock is used as physical capital input, and GDP is used as an output indicator. The GDP data 
is adjusted by using the GDP deflator in the past years. Using 2004 as the base year, the nominal GDP is converted into actual GDP to obtain comparable data after price adjustments. The Perpetual Inventory Method is used for the calculation of physical capital (fixed asset stock). The capital stock in a certain year is equal to the stock of the previous year minus depreciation plus the newly added capital for that year. The estimated data for the province's fixed asset stock from 2004 to 2018 are obtained, and the depreciation rate is taken as 10 percent. Energy consumption is obtained from annual data provided by the provincial statistical bureaus and the National Bureau of Statistics. Technical transaction data is adjusted by applying the GDP deflator index across the years. The data collection time range extends from 2004 to 2018 and the relevant raw data is taken from "the China Statistical Yearbook" (2005-2019).

The following indicators and relevant data are mainly used in the study: output value of the primary industry (G1, unit: 100 million Yuan), output value of the secondary industry (G2, unit: 100 million Yuan), output value of the tertiary industry (G3, unit: 100 million Yuan), material capital stock (K, unit: 100 million Yuan), primary human capital (H1, unit: ten thousand), intermediate human capital (H2, unit: ten thousand), senior human capital (H3, unit: ten thousand), technology turnover ( $\mathrm{T}$, unit: 100 million Yuan), and total energy consumption ( $E$, unit: 10,000 tons of standard coal).

Input factors make different contributions to economic growth. In order to obtain the output elasticity coefficient of different input factors, the model is estimated by applying the Stepwise Regression Method in accordance with equation (5). The data processing software is EViews 7.2. The regression results show that the function fitting is very good, and the sequence correlation is basically eliminated, and the fitting results are mostly significant at the 1 percent level. Factor output elasticity multiplied by the factor input growth rate is the contribution of each factor input to the economic growth rate. The total output growth rate minus the contribution of each factor to the total output growth rate is the contribution of technological progress to the economic growth rate.

3.3. Model Estimation Results and Contribution Rate Analysis. East China has advantages in talents and technology, but the economic growth path depends on the input of physical capital and energy, which makes it difficult for this part to demonstrate its advantages. A substantial amount of empirical research has found developing countries' dependence on energy. For example, Maria Del et al. [37] found that the energy output elasticity of the "BRIC countries" was 0.37 . Empirical analysis of the Chinese economic system shows that it is not just energy that can be understood as a driving force for economic growth. Energy factors can therefore be expanded and understood as "natural resource elements" or "resource factors represented by energy" in the study [38-40]. The subtle relationship between physical capital and human capital is embodied in the concept of "capital-labor substitution flexibility." If we can enhance the development of human capital under the existing conditions and appropriately increase the proportion of middle- and highlevel human capital, it will help to reduce our dependence on capital [41]. Labor is a strong substitute for energy, and capital and energy are replaced first and then complemented. The factors have different effects on the industries; for this reason, it is necessary to study the elasticity of output factors by referring to the three industries. The elasticity of output factor, which is calculated by referring to the three industries, is shown in Tables 1-3.

As shown in Table 1, the traditional primary industry mainly uses natural forces for production, and it has low requirements for technological progress and energy. As regional productivity develops, the production situation of the primary industry differs. An analysis of output factor elasticity enables us to see the respective characteristics of primary industry production in different regions. Table 1 shows that Shanghai's primary industry (calculated at comparable prices) has a negative growth ( -1.50 percent) and demonstrates that energy, high-level human capital, and physical capital play a significant role in the primary industry. Energy has delayed the decline of the primary industry. The growth of Jiangsu's primary industry depends on energy, innovation (technology trading), and intermediate human capital. Jiangsu's primary industry growth rate, driven by strong technology and energy, ranks first in East China. Zhejiang's primary industry depends on intermediate and advanced human capital. Anhui's primary industry depends on energy input. Fujian's primary industry depends on energy and intermediate human capital, and energy factors contribute to more than 90 percent of the growth of its primary industry. Jiangxi's primary industry relies on energy and intermediate human capital to achieve sustained growth. The average growth rate of Shandong's primary industry is second only to Jiangsu, and this high growth is attributable to the input of energy, innovation (technical transactions), medium human capital, and physical capital. Jiangsu and Shandong maintain high primary industry growth that is inseparable from investment in innovation (technology transactions). In most regions (except for Zhejiang), energy factors play a significant role in promoting the growth of the primary industry.

As shown in Table 2, in the East China region, Shanghai's secondary industry has the slowest growth rate. It is an economically developed region; therefore it has already achieved industrialization. It is difficult for the secondary industry to grow by a large margin. Investment in energy elements has helped to ensure the continued growth of Shanghai's secondary industry. Jiangsu's joint promotion of energy, innovation (technology trading), material, and human capital has enabled its secondary industry to maintain a growth rate of more than 8 percent. Energy has contributed more than 60 percent of the growth of secondary industries in Zhejiang, Anhui, and Jiangxi. The growth of secondary industries in Fujian and Shandong has mainly depended on the contribution of physical capital.

As shown in Table 3, in East China, physical capital is the main input factor that promotes the growth of the tertiary industry. In most regions (except for Jiangxi), physical capital has a significant effect on the growth of the tertiary 
TABLE 1: Output elasticity of primary industry.

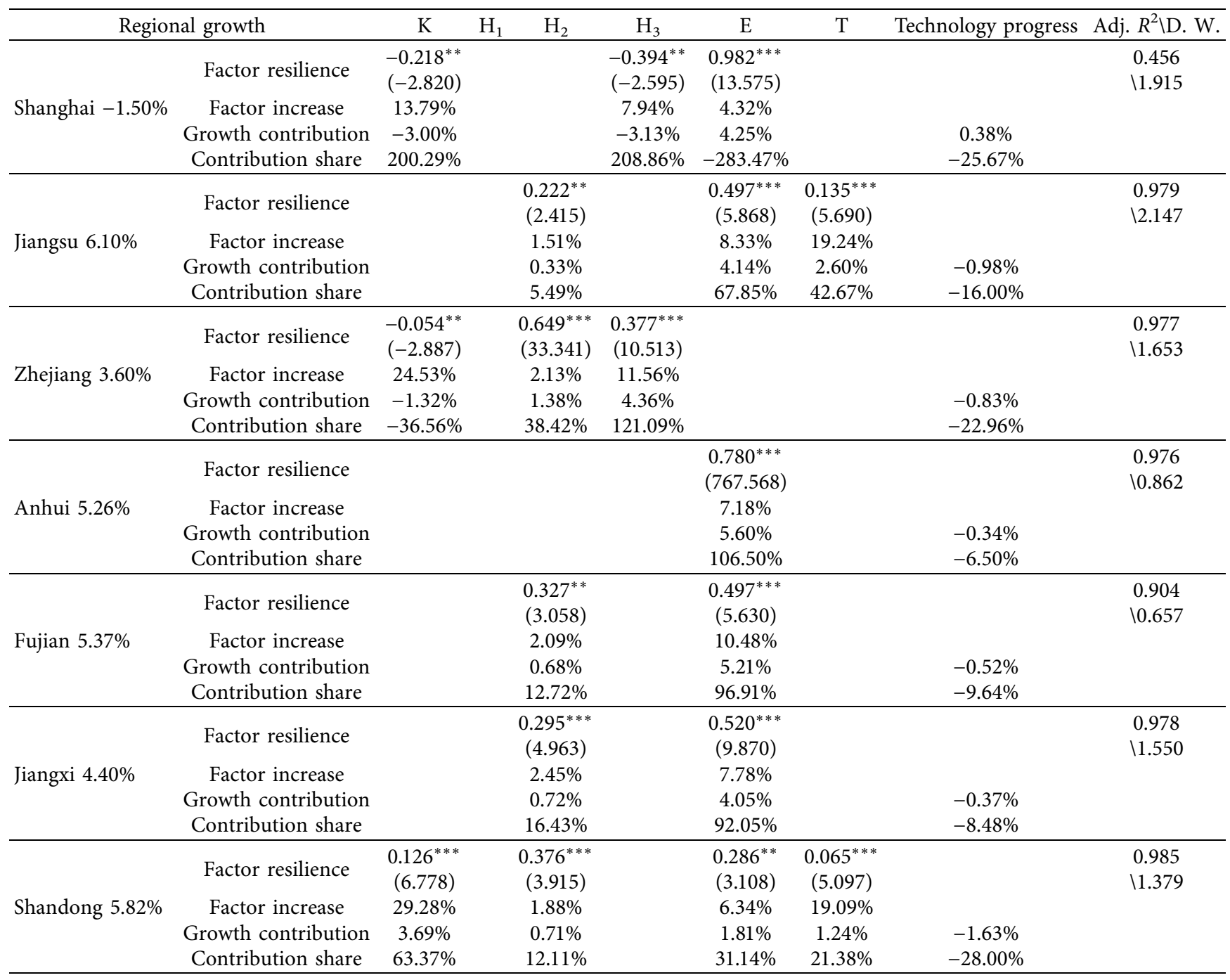

Note. The interpreted variable is $\operatorname{lnG} 1 .{ }^{*},{ }^{* *}$, and ${ }^{* * *}$ are, respectively, significant at $10 \%, 5 \%$, and $1 \%$ levels. The $T$ values are in parentheses.

industry, as shown by its contribution rate of more than 70 percent. The growth of the tertiary industry in Shanghai, Zhejiang, and Fujian benefited from physical and human capital. Energy factors played an important role in the growth of the tertiary industry in Anhui and Jiangxi. The elements of innovation (technology transactions) have significantly affected the growth of the tertiary industry in Jiangsu and Shandong that are, respectively, first and second in the ranking for the growth rate of East China's tertiary industry. The elements of innovation (technology transactions) are positively and significantly related to industrial development and are conducive to the formation of regional industrial competitive advantages.

3.4. Simulation Model Construction and Data Simulation. The economic system is nonlinear and counterintuitive, and a System Dynamics Method is better suited to describing a complex economic system. The model regression results set out in Tables 1-3 help to construct a simulation system for economic growth which is based on the economic growth subsystems of seven provinces and cities. The system dynamics model is more concise and clearer when it is based on economic theoretical analysis and data regression results.

Different subsystems have their own characteristics, and their requirements for input elements diverge. Some regions depend on a variety of input factors for economic growth, while others require fewer input factors. The Shanghai subsystem has the smallest number of input elements. The main input elements of the economic growth system are advanced human capital, energy consumption, and physical capital; the elements of innovation (technology transactions) are not reflected in the system. The volume of technological transactions in Shanghai is very high, but its contribution to Shanghai's economic growth is limited, which reflects the characteristics of innovative externalities. It is important to note that innovative elements contribute more to the economic growth of other regions. Jiangsu has the biggest number of input factors in the subsystem, and all the economic model's factors (see equation (4)) are found to 
TABLE 2: Output elasticity of secondary industry.

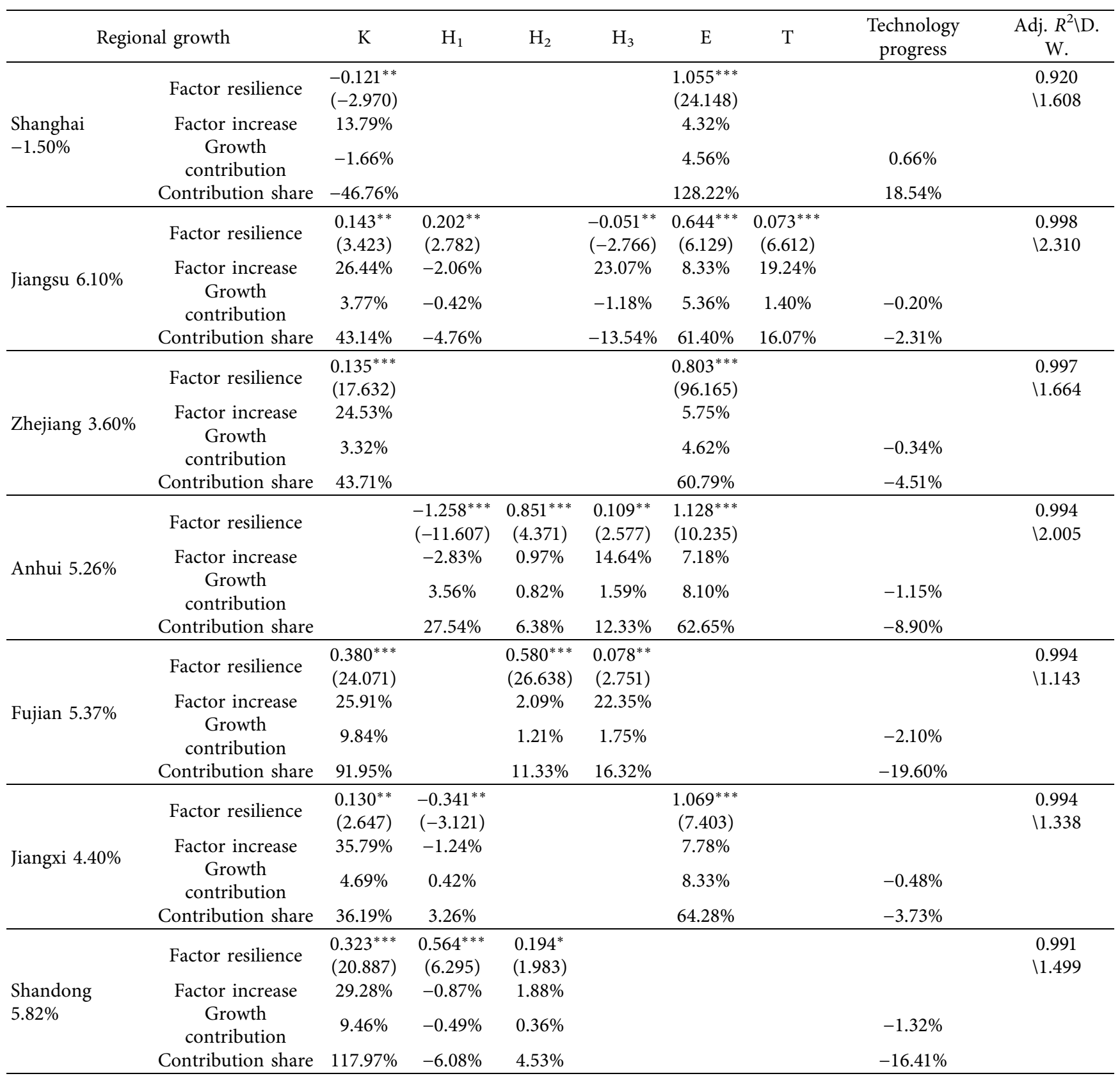

Note. The interpreted variable is $\operatorname{lnG} 2 .^{*},{ }^{* *}$, and ${ }^{* * *}$ are, respectively, significant at 10,5 , and 1 percent levels. The $T$ value is in parentheses.

positively affect economic growth. In particular, innovation factors are found to have significantly contributed to the development of Jiangsu's first, second, and tertiary industries.

The diversification of input factors in the economic system can reduce excessive dependence on a certain production factor. The positive effect of innovative elements can ensure the sustainability of growth, which raises the question of how a change in factor input will impact the existing economic system. System simulation helps to answer this question by simulating the result of changing input factors in the economic system. This research will use Vensim 5 software to build a system dynamics simulation model (see Figure 1).
When constructing the model, the output factor elasticity and factor growth rate data are used in Tables 1-3. Taking the Shanghai subsystem in Figure 1 as an example, the variables in the system are Shanghai GDP, Shanghai Primary Industry Growth Rate (Shanghai GDP1gr), Shanghai Secondary Industry Growth Rate (Shanghai GDP2gr), Shanghai Tertiary Industry Growth Rate (Shanghai GDP3gr), Shanghai Primary Industry Output Value (shg1), Shanghai Secondary Industry Output Value (shg2), Shanghai Third Industrial output value (shg3), Shanghai senior human capital growth rate (Shanghai H3), Shanghai physical capital growth rate (shanghaiK), and Shanghai energy consumption growth rate (shanghaiE). 
TABLE 3: Output elasticity of tertiary industry.

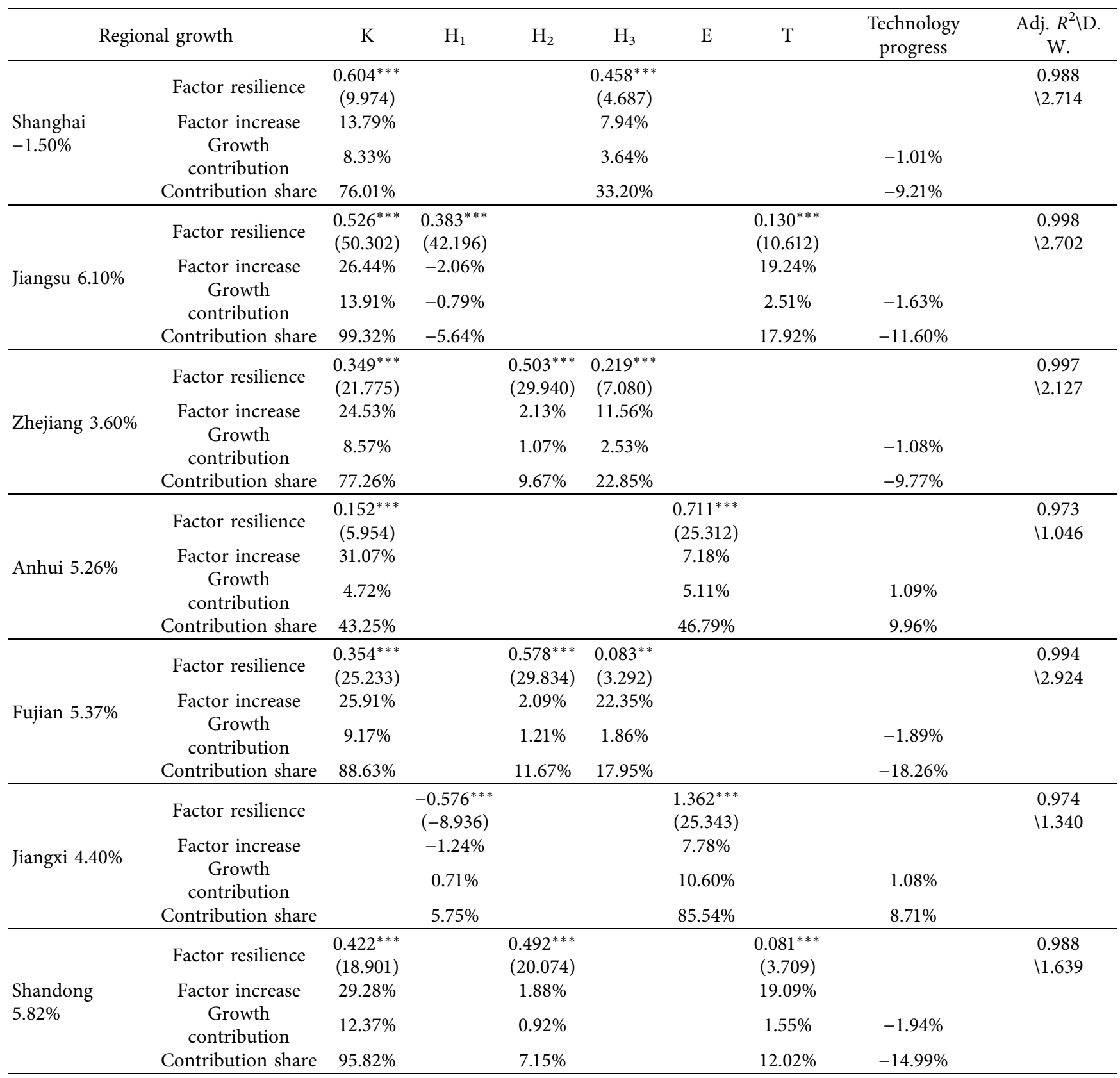

Note. The interpreted variable is $\operatorname{lnG} 2 .^{*},{ }^{* *}$, and ${ }^{* * *}$ are, respectively, significant at 10,5 , and 1 percent levels. The $T$ value is in parentheses.

The average value of relevant data during the period of 2004-2018 is inserted into the model as the initial variable value, and the simulated data that is obtained is then compared against the original real data. The average error is found to be 10.73 percent, and it is observed that the simulation model can reproduce the economic growth system to a good level. The data simulation process is as follows: fix the values of other variables, increase the growth rate of a certain input factor, and compare changes in the total GDP of East China under the condition of increasing the input of different factors. In turn, all the same elements in the economic growth model are given a $1 \%$ increase in each cycle compared to the previous cycle, and the simulation cycle runs for 10 times. The trend of the simulation data of the GDP total indicator is shown in Figure 2.

As shown in Figure 2, the total GDP increase caused by the increase in factor inputs is sorted from large to small: $E>K>H_{2}>\mathrm{H}_{1}>H_{3}>\mathrm{T}$. The effect of factor input and output shows that East China's current economic growth mainly relies on energy and material capital input. In other words, energy and material capital input are suitable for the region's current economic system, and regional economic growth is still extensive. The high-level human capital and innovation (technology transaction) elements that reflect technology and innovation capabilities will struggle to play a 


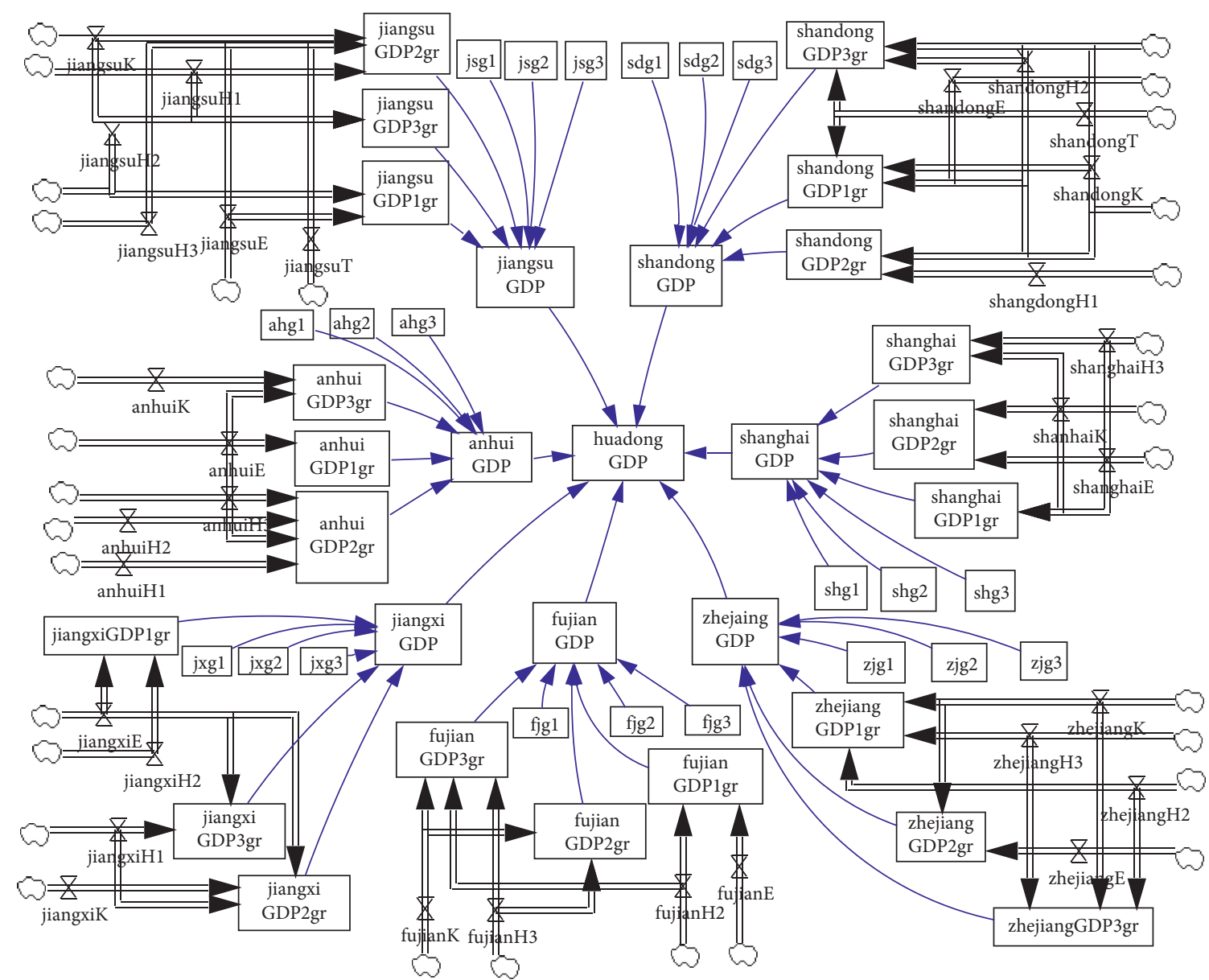

FIgURE 1: Flowchart of an economic growth simulation system in East China.

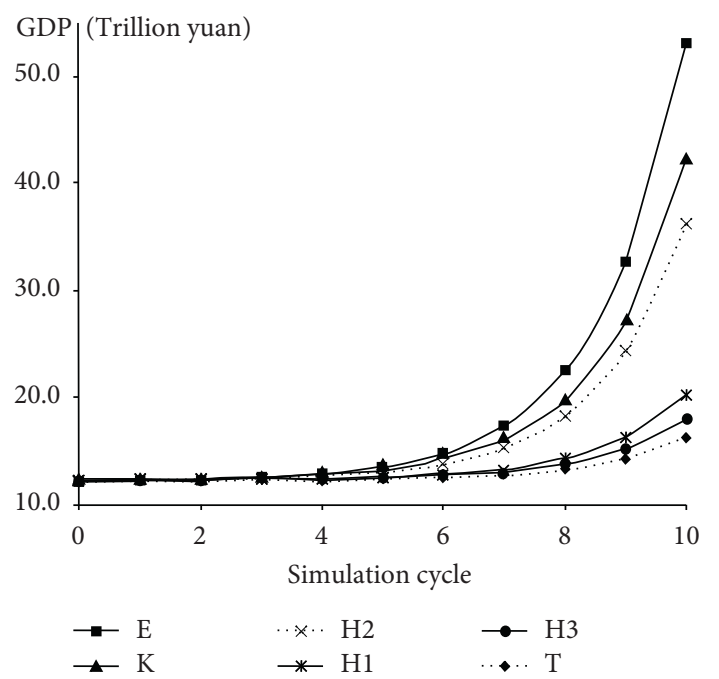

FIGURE 2: Simulation results of the effect of factor input on economic growth.

leading role in generating growth in the current economic system.

When the simulation model is used to simulate the input and output of factors, the input cost of various input factors is not considered. The cost of 1 percent increase for different input factors is different and does not consider the feasibility of increasing the input of factors. For example, if there is an energy crisis, there may not be sufficient energy even if funds are in place. The external boundary of this study's economic model is therefore relatively stable, and there are not too many cycles of simulation.

3.5. Measurement of Technological Progress and Growth Convergence. Technological progress provides a continued impetus for economic growth. At present, in the context of "new normal" economic growth, supply-side reforms, and structural adjustments, with reference to international experience, we are thinking about how to promote technological progress and make full use of technological progress under the current situation. Technological progress is affected by technological change and efficiency. The former can improve or create new things, such as new product development. The latter refers to the reduction of inefficient activities in the process of production operations, such as economies of scale and management activities. The type of technological progress depends on different combinations of two elements: technological change and efficiency change. Both forms of change develop positively, and then 
technological progress is also developing positively, or at least one of the two elements is developing positively and plays a dominant role. Technological changes can change the frontier of production, and improvements in efficiency are evidenced when production move to the forefront.

Dynamic imbalance is the "normal" of a healthy economy. Innovation is an activity of creation and a destruction of old methods and products. During the process of technological progress, the impact of technological changes is significantly higher than that of efficiency changes, as is confirmed by the practice of developed economies. Since the middle of the eighteenth century, the three industrial revolutions in human history have been dominated by technological advances. The promotion of technological and efficiency changes requires the investment of a large amount of human, material, financial, and other resources, which need to be weighed in the allocation of innovative resources.

In order to further analyze technological progress and its growth convergence, total factor productivity is used as a measure of technological progress, and the Malmquist Index is measured. The input-based total factor productivity change (tfpch) can be expressed by the Malmquist Index, namely,

$$
M_{0}^{t+1}=\left[\frac{D^{t}\left(x_{0}^{t+1}, y_{0}^{t+1}\right)}{D^{t}\left(x_{0}^{t}, y_{0}^{t}\right)} \times \frac{D^{t+1}\left(x_{0}^{t+1}, y_{0}^{t+1}\right)}{D^{t+1}\left(x_{0}^{t}, y_{0}^{t}\right)}\right] \text {. }
$$

The Malmquist Index can be combined with the data envelopment analysis (DEA) Method to measure changes in population productivity, and the index can be decomposed into two parts: efficiency (effch) and technology (techch). The formula of the Malmquist Index can be expressed as

$$
\begin{aligned}
M I & =\frac{D^{t+1}\left(x_{0}^{t+1}, y_{0}^{t+1}\right)}{D^{t}\left(x_{0}^{t}, y_{0}^{t}\right)}\left[\frac{D^{t}\left(x_{0}^{t+1}, y_{0}^{t+1}\right)}{D^{t+1}\left(x_{0}^{t+1}, y_{0}^{t+1}\right)} \times \frac{D^{t}\left(x_{0}^{t}, y_{0}^{t}\right)}{D^{t+1}\left(x_{0}^{t}, y_{0}^{t}\right)}\right] \\
& =\text { effch } \times \text { techch. }
\end{aligned}
$$

Total factor productivity changes can be decomposed into technology changes (techch) and efficiency changes (effch), and efficiency changes can be decomposed into pure technical efficiency changes (pech) and scale efficiency changes (sech); namely,

$$
\begin{aligned}
& \text { tfpch }=\text { effch } \times \text { techch, } \\
& \text { effch }=\text { pech } \times \text { sech, }
\end{aligned}
$$

where effch $>1$ means efficiency improvement and effch $<1$ means efficiency reduction; techch $>1$ means technological progress, and techch $<1$ means technological decline. The input-output index is determined on the basis of the Cobb-Douglas Production Function. Two input-output models of A and B are used to calculate the Malmquist Index. Model A (based on the C-D function after factor expansion) selects primary, intermediate, and advanced human capital, fixed assets, energy, and technology transaction volume as input indicators; meanwhile, output indicators are the added value of the first, second, and tertiary industries. Model B (based on the classic C-D function) selects total human capital and fixed assets as input indicators and output indicator as GDP. The calculation results are shown in Tables 4 and 5 (DEAP software is used to calculate the Malmquist Index).

As shown in Table 4, there are obvious differences between the calculation results of models A and model B (see Figure 3). The data of model A indicates that the changes in East China's total factor productivity are mainly caused by technological changes and also indicates that the efficiency change has remained at 1 . The data of model $B$ shows that the total factor productivity change in East China is composed of technological and efficiency changes.

As shown in Figure 3, the authors find that the total factor productivity changes measured by models $\mathrm{A}$ and $\mathrm{B}$ show clear fluctuations, and the total factor productivity measured by model A fluctuates more. Model A also contains more diverse input and output elements than model B. Theoretical analysis, when combined with factor contribution calculation and data simulation results, suggests that model A more accurately reflects the real economic system. There is no obvious feature of technological progress in East China, as this is subject to different combinations of two elements, specifically technological change and efficiency change, which have not developed simultaneously. East China's production frontier has not significantly changed, and production activities have moved slightly away from the production frontier.

The data in Table 5 referring to model A suggests that, during the research period, East China has maintained an average annual total factor productivity change of -0.1 percent. Efficiency sources are the main source of the slight decline in total factor productivity. Shanghai shows the highest level of change in total factor productivity and maintains an annual growth rate of 3.9 percent. Changes in total factor productivity in Jiangsu, Zhejiang, and Shandong are all greater than 1 . The measured values of various indicators of model B are slightly lower than those of model A. The factor productivity of the multifactor production function model is better than the classic model's counterpart. The efficiency change value fluctuates around the index value 1, the fluctuation range is small, and the efficiency change presents a convergence characteristic, which indicates that efficiency changes tend to be stable. During the study period, there appeared to be no obvious technological progress in East China as a whole, which once again illustrated the extensive characteristics of economic growth in East China. The sustainability of economic growth in East China does, however, continue to be confronted by challenges. Shanghai, Jiangsu, and Zhejiang are provincial-level regions that can be regarded as engines of technological progress in East China.

\section{Results and Discussion}

In the case of the determinism of economic growth, there continues to be disputes about capital, human, and system change and technology determinism. Given China's ongoing economic transformation and development, a heterogeneous multifactor model that incorporates human and 
TABLE 4: Malmquist Index summary of annual means.

\begin{tabular}{lcccccccccc}
\hline Year & tfpch & techch & effch & pech & sech & tfpch & techch & effch & pech & sech \\
\hline 2005 & 0.805 & 0.805 & 1.000 & 1.000 & 1.000 & 0.817 & 0.777 & 1.052 & 1.025 & 1.026 \\
2006 & 1.207 & 1.208 & 0.999 & 1.000 & 0.999 & 0.838 & 0.849 & 0.987 & 0.998 & 0.989 \\
2007 & 0.949 & 0.948 & 1.001 & 1.000 & 1.001 & 0.862 & 0.894 & 0.964 & 0.994 & 0.970 \\
2008 & 0.997 & 0.997 & 1.000 & 1.000 & 1.000 & 0.875 & 0.916 & 0.955 & 0.998 & 0.957 \\
2009 & 0.970 & 0.970 & 1.000 & 1.000 & 1.000 & 0.901 & 0.981 & 0.918 & 0.986 & 0.931 \\
2010 & 0.892 & 0.892 & 1.000 & 1.000 & 1.000 & 0.901 & 0.965 & 0.933 & 0.986 & 0.947 \\
2011 & 1.009 & 1.009 & 1.000 & 1.000 & 1.000 & 0.946 & 0.976 & 0.968 & 0.956 \\
2012 & 0.992 & 0.992 & 1.000 & 1.000 & 1.000 & 0.942 & 0.984 & 0.958 & 0.938 \\
2013 & 1.003 & 1.003 & 1.000 & 1.000 & 1.000 & 0.983 & 1.014 & 0.969 & 0.952 \\
2014 & 0.968 & 0.968 & 1.000 & 1.000 & 1.000 & 0.994 & 1.029 & 0.966 & 0.952 \\
2015 & 1.350 & 1.350 & 1.000 & 1.000 & 1.000 & 1.478 & 1.516 & 0.975 & 0.969 \\
2016 & 1.007 & 1.012 & 0.994 & 1.000 & 0.994 & 1.085 & 1.104 & 0.983 & 0.985 \\
2017 & 0.943 & 0.938 & 1.006 & 1.000 & 1.006 & 1.081 & 1.079 & 1.002 & 0.992 \\
2018 & 1.000 & 1.007 & 0.993 & 1.000 & 0.993 & 1.073 & 1.056 & 1.016 & 1.007 \\
Mean & 0.999 & 1.000 & 0.999 & 1.000 & 0.999 & 0.973 & 0.999 & 0.974 & 0.981 \\
Model & & & $\mathrm{A}$ & & & & & 0.019 \\
\hline
\end{tabular}

TABLE 5: Malmquist Index summary of areas means.

\begin{tabular}{lcccccccccc}
\hline Region & tfpch & techch & effch & pech & sech & tfpch & techch & effch & pech & sech \\
\hline Shanghai & 1.039 & 1.039 & 1.000 & 1.000 & 1.000 & 1.026 & 1.026 & 1.000 & 1.000 & 1.000 \\
Jiangsu & 1.027 & 1.027 & 1.000 & 1.000 & 1.000 & 1.011 & 1.010 & 1.001 & 1.000 & 1.001 \\
Zhejiang & 1.016 & 1.016 & 1.000 & 1.000 & 1.000 & 0.989 & 1.009 & 0.981 & 0.986 & 0.994 \\
Anhui & 0.966 & 0.966 & 1.000 & 1.000 & 1.000 & 0.933 & 0.979 & 0.953 & 0.959 & 0.994 \\
Fujian & 0.987 & 0.987 & 1.000 & 1.000 & 1.000 & 0.987 & 0.997 & 0.991 & 0.982 & 1.009 \\
Jiangxi & 0.958 & 0.958 & 1.000 & 1.000 & 1.000 & 0.905 & 0.972 & 0.931 & 0.958 & 0.972 \\
Shandong & 1.004 & 1.008 & 0.996 & 1.000 & 0.996 & 0.964 & 0.999 & 0.965 & 0.980 & 0.985 \\
Mean & 0.999 & 1.000 & 0.999 & 1.000 & 0.999 & 0.973 & 0.999 & 0.974 & 0.981 & 0.994 \\
Model & & & $\mathrm{A}$ & & & & & & B \\
\hline
\end{tabular}

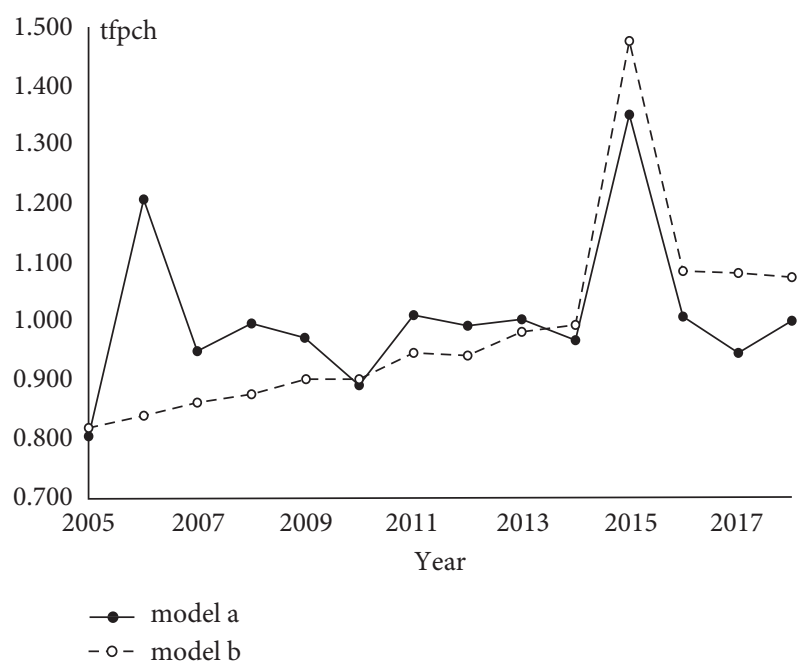

Figure 3: Trend of simulation results of model A and B.

material capital and innovation and energy consumption can better describe the drivers of economic growth in Eastern China and can also more effectively distinguish the growth process of different provinces and industries. A combination of multifactor growth model regression analysis and system dynamics simulation research will be able to better simulate the economic growth process.

In turning to East China's overall economic system, we have found physical capital and energy are the main driving forces behind economic growth. The simulation results show that increasing the input of energy, material capital, and intermediate human capital will be most conducive to economic growth. The study of the three industries suggests that the main driving factors behind the growth of the primary industry are energy and intermediate human capital; the main driving factors behind the growth of the secondary industry are physical capital and energy; the main driving factors in the growth of the tertiary industry are physical capital (intermediate and senior), human capital, and energy. East China still has not shaken off the mode of extensive growth and the regional advantages of innovation; high-level human capital has not yet been fully utilized. The mode of extensive growth is difficult to sustain over a long period of time and cannot meet the requirements of supply-side reform.

The results of Malmquist Index calculation indicate there is no obvious technological progress in East China as a whole, which once again illustrates the extensive characteristics of economic growth in this region. The sustainability of economic growth in East China continues to be confronted with challenges. Shanghai, Jiangsu, and Zhejiang are 
provincial-level regions that can be regarded as engines of technological progress in East China.

With regard to the study of different provinces, Shanghai and Jiangsu can be viewed as two typical regions. The main input elements of Shanghai's economic growth subsystem are energy, physical capital, and advanced human capital. Shanghai is the engine of economic growth in East China and even the whole country; it has an adequate supply of people (high-level human capital), finance (material capital), and the materials (energy) required for economic development and therefore presents a high-input and output growth model. If Shanghai continues to maintain the current economic system, and if the city continues to be the region's locomotive of economic growth, a large amount of material capital, energy, and high-level human capital will be required as factor inputs. This undoubtedly entails a high consumption of input factors, and the city may not be able to maintain high growth in factors such as material capital, energy, and advanced human capital in the future. The input elements required by Jiangsu's economic subsystem are more diversified, and its innovation elements have a significant effect on economic growth. Elementary, intermediate, and senior human capital have their own uses. This model is more adaptable and resistant to human capital supply risks than the Shanghai subsystem, which mainly relies on senior human capital, and it can also provide more diverse employment opportunities. In order to alleviate the pressure on Shanghai as a growth engine, the Jiangsu growth model should be promoted, and Jiangsu should be endorsed and promoted as a leading producer of economic growth in the region; in addition, provinces with innovation capabilities and innovative output (such as Shandong) should be elevated and celebrated as new economic growth points.

\section{Conclusions}

In the process of economic growth in East China, material capital is still the main driving force. However, energy factors do have a specific research significance. Although they do not currently play a leading role in producing economic growth, they have been shown to be a huge driving force behind growth in system simulation. In the future, material capital will play a role in output elasticity and growth rate. There may be a declined importance of energy as a result. Simple and extensive increases in energy input will increase environmental pollution and overwhelm the environment. Measures such as the development of new energy and clean energy and the optimization of energy consumption structure could improve the efficiency of the allocation of energy elements and also promote relevant technological progress.

Separate regions have different economic growth patterns and levels of need for input elements. The output elasticity of an input element in a certain province is low, and the output elasticity of another area may be relatively high. Factor Utilization Efficiency could be improved if the rational flow of input factors is promoted across regions. The structural optimization and rational flow of input factors will promote the improvement of the industrial/economic structure, encourage supply-side reforms, and drive the transformation of the economic system from an extensive growth model to a sustainable growth alternative.

\section{Data Availability}

The experimental data used to support the findings of this study are included within the article.

\section{Conflicts of Interest}

The authors declare that they have no conflicts of interest.

\section{Acknowledgments}

This work was supported by the National Social Science Foundation of China (no. 20BGL203).

\section{References}

[1] J. Mincer, "Economic development, growth of human capital, and the dynamics of the wage structure," Journal of Economic Growth, vol. 1, no. 1, pp. 29-48, 1996.

[2] J. Čadil, L. Petkovová, and D. Blatná, "Human capital, economic structure and growth," Procedia Economics and Finance, vol. 12, pp. 85-92, 2014.

[3] A. V. Suvorov, N. V. Suvorov, V. G. Grebennikov et al., "Approaches to measuring the dynamics and structure of human capital and assessing its accumulated impact on economic growth," Studies on Russian Economic Development, vol. 25, no. 3, pp. 215-224, 2014.

[4] C. Amparo, "The age structure of human capital and economic growth," Oxford Bulletin of Economics \& Statistics, vol. 81, no. 2, pp. 394-411, 2019.

[5] Y. Wang and S. Liu, "Education, human capital and economic growth: empirical research on 55 countries and regions (19602009)," Theoretical Economics Letters, vol. 6, no. 2, pp. 347-355, 2016.

[6] A. Shaimerdenova and J.-C. Garcia-Zamor, "Influence of human capital on economic growth: a comparative analysis of education development in Kazakhstan, South Korea, Singapore and Malaysia," Journal of Public Administration and Governance, vol. 7, no. 3, pp. 30-46, 2017.

[7] S. S. Belavi and V. Sharada, "Human capital formation in India: an economic analysis," International Journal of Management and Development Studies, vol. 6, no. 5, pp. 10-22, 2017.

[8] K. Michå̊, "How taxes, education and public capital influence economic growth in Poland," Contemporary Economics, vol. 12, no. 3, pp. 337-360, 2018.

[9] K. Ogundari and T. Awokuse, "Human capital contribution to economic growth in Sub-Saharan Africa: does health status matter more than education?" Economic Analysis and Policy, vol. 58, pp. 131-140, 2018.

[10] E. Moe, "Energy, industry and politics: energy, vested interests, and long-term economic growth and development," Energy, vol. 35, no. 4, pp. 1730-1740, 2010.

[11] D. I. Stern, "The role of energy in economic growth," Annals of the New York Academy of Sciences, vol. 1219, no. 1, pp. 26-51, 2011.

[12] N. Apergis and C. F. Tang, "Is the energy-led growth hypothesis valid? New evidence from a sample of 85 countries," Energy Economics, vol. 38, pp. 14-21, 2013. 
[13] F. A. Dieck-Assad and E. Peralta, "Energy and capital inputs: cornerstones of productivity growth in Mexico: 1965-2004," Empirical Economics, vol. 44, no. 2, pp. 563-590, 2013.

[14] J. Kim and E. Heo, "Asymmetric substitutability between energy and capital: evidence from the manufacturing sectors in 10 OECD countries," Energy Economics, vol. 40, pp. 81-89, 2013.

[15] Q. Huang, "China's industrialization process: stage, feature, and prospect," Chinese Journal of Urban and Environmental Studies, vol. 1, no. 1, pp. 5-18, 2013.

[16] B. Lin and C. Xie, "Energy substitution effect on transport industry of China based on trans-log production function," Energy, vol. 67, pp. 1166-1178, 2014.

[17] R. Bellais, "Post keynesian theory, technology policy, and long-term growth," Journal of Post Keynesian Economics, vol. 26, no. 3, pp. 419-440, 2004.

[18] R. E. Lucas, "On the mechanics of economic development," Journal of Monetary Economics, vol. 22, no. 1, pp. 3-42, 1988.

[19] C. Gregory, A Farewell to Alms: A Brief Economic History of the World, Princeton University Press, Princeton, NJ, USA, 2009.

[20] R. J. Barro, "Economic growth in a cross-section of countries," Quarterly Journal of Economics, vol. 106, pp. 501-526, 1991.

[21] S. M. Miller and M. P. Upadhyay, "The effects of openness, trade orientation, and human capital on total factor productivity," Journal of Development Economics, vol. 63, no. 2, pp. 399-423, 2000.

[22] P. Romer, "Endogenous technological change," Journal of Political Economy, vol. 98, no. 5, pp. 71-102, 1990.

[23] J. Vandenbussche, P. Aghion, and C. Meghir, "Growth, distance to frontier and composition of human capital," Journal of Economic Growth, vol. 11, no. 2, pp. 97-127, 2006.

[24] J. Benhabib and M. M. Spiegel, "The role of human capital in economic development evidence from aggregate crosscountry data," Journal of Monetary Economics, vol. 34, no. 2, pp. 143-173, 1994.

[25] M. Bils and P. Klenow, "Does schooling cause growth?" The American Economic Review, vol. 90, pp. 328-335, 2000.

[26] L. Pritchett, "Where has all the education gone?" The World Bank Economic Review, vol. 15, no. 3, pp. 367-391, 2001.

[27] A. B. Krueger and M. Lindahl, "Education for growth: why and for whom?" Journal of Economic Literature, vol. 39, no. 4, pp. 1101-1136, 2001.

[28] E.-P. Gallie and D. Legros, "How do spatial spillovers diffuse in science-industry interactions? The case of French biotech sector," Economics of Innovation and New Technology, vol. 16, no. 8, pp. 635-652, 2007.

[29] J. L. Furman, M. E. Porter, and S. Stern, "The determinants of national innovative capacity," Research Policy, vol. 31, no. 6, pp. 899-933, 2002.

[30] U. Cantner and A. Pyka, "Classifying technology policy from an evolutionary perspective," Research Policy, vol. 30, no. 5, pp. 759-775, 2001.

[31] F. Michael, "R\&D-cooperation and the efficiency of regional innovation activities," Cambridge Journal of Economics, vol. 28, pp. 829-846, 2004.

[32] J. C. Guan and K. H. Chen, "Measuring the innovation production process: a cross-region empirical study of China's high-tech innovation," Technovation, vol. 30, no. 5/6, pp. 348-358, 2010.

[33] H. Pinto and J. Guerreiro, "Innovation regional planning and latent dimensions: the case of the Algarve region," The Annals of Regional Science, vol. 44, no. 2, pp. 315-329, 2010.
[34] C. W. Eric, "R\&D efficiency and economic performance: a cross-country analysis using the stochastic frontier approach," Journal of Policy Modeling, vol. 29, no. 2, pp. 345-360, 2007.

[35] K. Chen and J. Guan, "Measuring the efficiency of China's regional innovation systems: application of network data envelopment analysis (DEA)," Regional Studies, vol. 46, no. 3, pp. 355-377, 2012.

[36] G. Dzemydaitè, I. Dzemyda, and B. Galinienè, "The efficiency of regional innovation systems in new member states of the European Union: a nonparametric DEA approach," Economics and Business, vol. 28, pp. 83-89, 2016.

[37] P. Maria Del, R. Pablo, and S.-B. Antonio, "Productive energy use and economic growth: energy, physical and human capital relationships," Energy Economics, vol. 49, pp. 420-429, 2015.

[38] W. Wei, W. Cai, Y. Guo, C. Bai, and L. Yang, "Decoupling relationship between energy consumption and economic growth in China's provinces from the perspective of resource security," Resources Policy, vol. 68, Article ID 101716, 2020.

[39] T. Wang, G. He, J. Guo, Y. Yin, and L. L. Li, "Energy consumption and economic growth in China's marine economic zones-an estimation based on partial linear model," Energy, vol. 205, Article ID 118028, 2020.

[40] J. Li and S. Li, "Energy investment, economic growth and carbon emissions in China-empirical analysis based on spatial Durbin model," Energy Policy, vol. 140, Article ID $111425,2020$.

[41] X. Wang, F. Yamauchi, and J. Huang, "Rising wages, mechanization, and the substitution between capital and labor: evidence from small scale farm system in China," $\mathrm{Ag}$ ricultural Economics, vol. 47, no. 3, pp. 309-317, 2016. 